\title{
SMOKING RELATED SYSTEMIC AND ORAL DISEASES
}

\author{
Sajith Vellappally ${ }^{1}, Z$ Zdeněk Fiala ${ }^{1}$, Jindra Šmejkalová ${ }^{1}$, Vimal Jacob $^{1}$, Rakesh Somanathan ${ }^{2}$
}

Charles University in Prague, Faculty of Medicine in Hradec Králové and University Hospital Hradec Králové, Czech Republic: Department of Hygiene and Preventive Medicine ${ }^{1}$, Department of Dentistry ${ }^{2}$

Summary: This article reviewed smoking related systemic diseases and oral diseases. Smoking is related to lung cancer, cardiovascular diseases and many other systemic diseases. Cigarette smoke affects the oral cavity first, so it is evident that smoking has many negative influences on oral cavity, for example, staining of teeth and dental restorations, wound healing, reduction of the ability to smell and taste, and development of oral diseases such as oral cancer, periodontitis, smoker's palate, smoker's melanosis, hairy tongue, leukoplakia, oral candidiasis and implant survival rate. The article also discusses the relationship between smoking and dental caries in detail.

Key words: Smoking; Systemic diseases; Oral diseases; Dental caries

\section{Introduction}

Tobacco is one of the major toxic agents in our civilization. Tobacco use and smoking is one of the most common causes of mortality and morbidity in developed and developing countries in present times. Tobacco comes from a plant that is native to America, around Peru and Ecuador (51). Tobacco was introduced to Europe from America in the fifteenth century, first being used in medicinal purposes. Later, it came to be burnt in pipes for pleasure on a large scale for nearly 100 years in England and subsequently in Europe as well as the rest of the world. Pipe smoking gave way to the use of tobacco as snuff and in time to cigars and cigarettes varying from country to country, until cigarette smoking became the dominant form in most of the developed countries between the two world wars (20).

It has been reported that tobacco kills 5 million people annually, and has been estimated that by mid 2020, the figure will increase to about 10 million a year, which means it would be the cause of most death occurring in developing countries (75). Over 1.1 billion adults (29\% of the adult population) are current smokers of cigarettes worldwide (5). Cigarette smoke is highly dynamic and has a complex matrix consisting of a gas phase and a particulate phase with more than 3800 compounds. Among these compounds, 60 of them are well-established carcinogens in animals and 15 of them are carcinogens in humans. Some of the carcinogens found in cigarette smoke include polycyclic aromatic hydrocarbons, aldehydes, arsenic, nickel and cadmium $(1,26)$. Smoking not only harms smokers but also harms the people around them.
This review mainly discusses the systemic effect and oral effect of smoking and specifically analyzes the effect of smoking on dental caries.

\section{Smoking and systemic diseases}

Presently, cigarette smoking has been found to be positively associated with nearly 40 diseases and causes of death and to be negatively associated with eight or nine. In some instances the positive associations are largely or wholly due to confounding, but the great majority has been shown to be causal in character (20). Cigarette smoking reduces life span by an average of 7 years, and tobacco consumption accounts for a shortening of disease free life by 14 years (11).

The medical evidence of harm caused by smoking has been accumulating for 200 years, at first in relation to cancers of the lip and mouth, and then in relation to vascular diseases and cancer of the lung. In the beginning, the evidence was ignored until five case-control studies relating smoking to the development of lung cancer were published in $1950(20,51)$.

Lung cancer is the most common tobacco-related cause of cancer. Statistically, one case of pulmonary carcinoma has been reported for every 3 million cigarettes smoked (54). Cigarette smoke contains several carcinogens that alter biochemical defense systems in the body leading to lung cancer (17), the strongest determinant being the duration of smoking and risk increasing with the number of cigarettes smoked (53).

Smoking causes a wide range of diseases, including many types of cancers, coronary heart disease, stroke and 
peripheral vascular diseases (22). Smoking also increases the chance of developing cancer of the pancreas, renal pelvis, and urinary bladder. It is also associated with the cancer of the liver, uterine cervix, nasal cavity, pharynx, larynx, esophagus, stomach and kidney $(18,29,71)$.

Smoking is a known cause for chronic obstructive pulmonary disease (COPD) (8). Tars produced within tobacco combustion contain irritant agents (acrolein, formaldehyde, etc.) and oxidative substances that are responsible for chronic bronchitis and emphysema (40). It has been observed that $80 \%$ of deaths from heart attacks in individuals under 45 are directly related to smoking. The chances of heart attack are twice as likely among smokers compared to nonsmokers. When a smoker quits smoking, his/her chances of heart attack decline to those of a non-smoker in about 6 months (15).

The most harmful compounds in tobacco smoke include carbon monoxide, arsenic, cadmium, cobalt and polycyclic aromatic hydrocarbons. Carbon monoxide is bound with haemoglobin to form carboxyhaemoglobin, which is a major cause of hypoxia and vascular accidents (40). Peptic ulcer is also more common in smokers than in non-smokers (22). Other potentially fatal diseases caused by smoking include respiratory heart disease, pneumonia, aortic aneurysm and ischaemic heart disease, which are the most common causes of death in developed countries (71). There is also a strong association between smoking and a number of common eye diseases, which include Graves' ophthalmopathy, age-related macular degeneration, glaucoma, and cataract (14).

The health effects of smoking are more serious for women than for men. In addition to the general health problems common to both genders, women face additional hazards (47). An example of this situation is the exposure of the fetus to maternal smoking. The exposure of mother to environmental tobacco smoke (ETS) can have a serious, sometimes life-threatening impact on the fetus. Such exposure increases the risk of spontaneous abortion, ectopic pregnancy, intrauterine growth retardation, premature membrane rupture, pre-term birth, retroplacental haematoma, placenta praevia, and sudden infant death (74).

Besides women, children are a very vulnerable poplation, particularly during the first year of their life. Their exposure to environmental tobacco smoke, or passive smoking, can induce serious short-term as well as long-term health effects (8). Children exposed to passive smoking have increased chances of chronic middle ear effusion, asthma attack, and changes in pulmonary function (21). Children of parents who smoke are more likely to encounter respiratory infections, pneumonia and bronchiolitis (48). Children who are exposed to passive smoking are potentially in danger of chronic cough, wheezing, running nose and excessive sneezing (48). Passive exposure of smoking during childhood increases a child's risk of leukemia and lymphoma during adulthood (21). It has been reported that maternal smoking during childhood increased a child's risk to become a young adult smoker (53).

\section{Smoking and oral diseases}

\section{Oral cancer}

Cigarette smoking and use of other types of tobacco products cause oral cancer (72). Oral cancer affects mostly middle aged or elderly people and is more common in men than in women. It constitutes $2-3 \%$ of all cancers worldwide (56). Cigarette smokers have two to five times higher risk of oral cancer than that of non-smokers (73), the risk increasing with the number of cigarettes and years smoked. On the other hand, cessation decreases the risk (26). Tobacco-specific N-nitrosamines, aromatic amines, and polycyclic aromatic hydrocarbons presented in mainstream tobacco smoke are considered the major carcinogens contributing to the risk of oral cancer from smoked tobacco products (73).

Although the underlying mechanisms are not known in detail, it is said that smoking could lead to cancer because carcinogens in tobacco smoke can induce changes in DNA. In recent years much attention has been given to smokingrelated mutations in a tumor suppressor gene coding for p53 protein. This protein is important in regulating cell proliferation and has a role in the repair of DNA damage (52). Smoking-related mutations in the gene may lead to an accumulation of DNA damage in the cells, which may play an important role in the development of cancer. It has been estimated that between $75 \%$ and $90 \%$ of all cases of oral cancer can be explained by the combined effect of smoking and alcohol use. This could be because alcohol dissolves certain carcinogenic compounds in tobacco smoke and/or because alcohol increases the permeability of the oral epithelium (56). Smoking and excessive alcohol intake synergistically increases the risk of the development of oral cancer (26).

\section{Oral leukoplakia}

Leukoplakia is believed to be a premalignant lesion associated with development of oral cancer (44). Tobacco smoking is the most important known etiological factor in development of oral leukoplakia (7). Cross-sectional studies show a higher prevalence rate of leukoplakia among smokers, with a dose-response relationship between tobacco use and oral leukoplakia, and intervention studies show a regression of the lesion after the cessation of smoking (7). Leukoplakias of the floor of mouth appeared to be significantly more often present in smokers than in non-smokers (60). Smokers have a six-fold increase in the risk of developing leukoplakia of the oral mucosa regard to non-smokers (12). Six European studies found smoking to be a cause in 56-97\% of leukoplakia patients. One of these studies also showed that the majority of smokers with leukoplakia (74 $\%)$ smoked more than 20 cigarettes per day compared to $34.5 \%$ of those without leukoplakia (12).

\section{Palatal leukokeratosis and smoker's melanosis}

Palatal leukokeratosis (smoker's palate) is an asymptomatic lesion associated with heavy pipe and cigar smoking 
usually appearing as white changes in hard palate, often combined with multiple red dots located centrally in small elevated nodule. It may disappear after smoking cessation $(34,56)$. It does reveal premalignant potential. Premalignant lesion like palatal keratosis is primarily associated with reverse smoking found mostly in South Asia (49).

Melanin pigmentation of the oral mucosa is normally seen in coloured races. Among Caucasian heavy smokers, $30 \%$ prevalence in pigmentation is seen, mostly on the attached gingiva (56). There are no symptoms, the change is not premalignant, and the pigmentation may be reversible upon cessation of smoking habit (34). A recent study in the Indian population showed that smokers were more likely to develop smoker's melanosis compared to other lesions (58).

\section{Oral candidiasis and hairy tongue}

Cigarette smoke is associated with a variety of changes in the oral cavity and it has an effect on oral commensal bacteria and fungi, mainly Candida species, which causes oral candidiasis. How cigarette smoke affects oral Candida is still controversial (65). Further studies and research need to find the exact etiology of smoking and oral candidiasis. It has been seen in the clinical experience that some Candida infections disappear following smoking cessation alone (34). Another oral lesion, "hairy tongue" or "black hairy tongue" is a benign condition characterized by hypertrophy of the filiform papillae that give the dorsum of the tongue a furry appearance associated sometimes with heavy smoking (76), but its etiology remains unclear.

\section{Aesthetics, smell and taste}

Discoloration of teeth, dental restorations and dentures are very frequent in smokers $(34,56)$. A recent cross sectional study conducted in British adults showed that $20 \%$ of smokers reported to have moderate and severe levels of tooth discoloration compared to $15 \%$ in non-smokers (4). Discoloration caused by smoking is more severe than that caused by tea and coffee consumption (56). Smoking is found to be associated with halitosis $(30,34)$. It has been seen that smoking influences the decreased function of smell $(34,56)$, and it is also associated with worsening of taste perception (59).

\section{Periodontitis}

Cigarette smoking is a significant risk factor for periodontal diseases (68), for example, increased loss of attachment (55), development and progression of periodontal inflammation $(23,32)$ and increased gingival recession (50). It has been found that smoking has a direct influence on the periodontal health status irrespective of the oral hygiene practice, age, race, gender, socioeconomic status or frequency of dental visits (35). Smoking affects various aspects of the host immune response. The mechanisms by which smoking enhances periodontal degradation are said to be the cumulative effect of elevation in levels of perio- dontal pathogens and modulation of the host immune response $(16,70)$. There is sufficient evidence that shows that smoking affects the innate and specific immune host responses $(33,39)$.

Antibody production is another protective host mechanism that is altered by smoking. Generally, smoking decreases serum IgG concentrations and decreases IgG2 antibody production in patients with early onset periodontitis (25). Smoking does not alter the bacterial plaque composition but on the other hand, it has been observed that the host's response to bacterial plaque is disturbed (46). The severity of alveolar bone destruction was found to be more expressed in smokers than in non-smokers $(10,38)$.

Chemical products and toxins in tobacco smoke may delay wound healing by impairing the biologic progression of healing and by inhibiting the basic cellular functions responsible for its initiation (35). Smokers have a decreased response to periodontal therapy compared to non-smokers $(32,46)$. Smoking has a strong negative influence on regenerative therapy, which includes osseous grafting, guided tissue regeneration or a combination of these treatments (34). It has been seen that the hemorrhagic response of periodontium is decreased in smokers compared to nonsmokers (9). On the whole, smoking related periodontal diseases consist of an increased and accelerated destruction of the supporting tissues of the teeth, with clinical symptoms of bone loss, pocket formation, and finally tooth loss.

\section{Wound healing}

Smoking appeared to have an adverse effect on the wound healing in the mouth after periodontal scaling, periodontal surgery or extraction wounds (34). It has been reported that increased frequency of smoking and smoking on the day of surgery significantly increased the incidence of alveolar ostitis known also as dry socket (3). The mechanism of impaired healing is likely associated with increased plasma levels of adrenaline and noradrenaline after smoking, leading to peripheral vasoconstriction and also impaired polymorphonuclear neutrophils function (34).

\section{Dental implants}

Smoking was found to be one of significant factors predisposing to implant failure. The use of tobacco involves a $15.8 \%$ risk of implant failure and the consumption of more than 20 cigarettes per day increased this risk up to $30.8 \%$ (57). Study has also suggested as an ongoing detrimental effect around the successfully integrated maxillary implants of smokers, with significantly greater bleeding index, mean peri-implant pocket depth, peri-implant inflammation and radiographically descendible mesial and distal bone loss (24). Studies on fixed implant prostheses proved that smoking correlated more strongly with marginal bone loss around implants (19). Because of all these proved effect of smoking on implant success, latest studies pertaining implants success exclude heavy smokers from their potential participants $(64,63)$. 


\section{Smoking and dental caries}

Smoking and its relation to dental caries is a subject of controversy, however several studies indicate an association with smokeless tobacco and caries, particularly in terms of root surface caries. This may be due to high proportion of sugar in some type of smokeless tobacco (69). It is interesting to note that maternal smoking and environmental tobacco smoke is also considered as a risk factor for dental caries in children $(62,72)$. .

Schmidt, in 1951, reported that the increase in tobacco smoking was followed by a decrease in caries rate (61). Smoking increases thiocyanate level in saliva. Thiocyanate, a normal constituent of saliva, was found to have a possible caries inhibiting effect $(34,56)$. On the other hand, studies showed that smoking is associated with lower salivary cystatin activity and output of cystatin $\mathrm{C}$ during gingival inflammation. Cystatins are thought to contribute to maintaining oral heath by inhibiting certain proteolytic enzymes. In addition, studies have confirmed from earlier results that there were no significant differences in salivary flow rates between smokers and non-smokers $(34,41)$. The decreased buffering effect of smoker's saliva and the higher number of lactobacilli and $S$. mutans group may indicate an increased susceptibility to caries $(34,56)$. To date, several investigators have discovered a correlation between increased smoking level and occurrence of dental caries $(6,13,31$, 36). For example, in 1952, Ludwick and Massler reported that individuals who smoked more than 15 cigarettes daily had significantly higher number of decayed, missing, and filled teeth (43). Ainamo found that increased smoking results in significantly high number of decayed surfaces per dentition (2). In 1990, Zitterbart confirmed an association between smoking and the prevalence of dental caries in adult males. Smokers had a significantly higher DMFT (Decayed, Missing, and Filled Teeth) score, untreated decayed surfaces, and missing surfaces. More cigarettes consumed per day resulted in more missing tooth surfaces in a smoker's mouth (77). Statistical analyses from a study in Sweden in 1991 showed that smoking, as a habit and an increased number of cigarettes smoked per day, are positively correlated with the increased number of decayed, missing and filled teeth and number of initially decayed proximal surfaces (28). Although studies did not establish a causative relationship, a recent study done on American female population in 2006, showed a correlation between cigarette smoking and the presence of dental caries (27).

Most of the studies mentioned above have taken into consideration other contributing factors to dental caries such as age, tobacco habits other than smoking, oral hygiene habits, eating habits, and preventive visits to dentist (dental recalls) and overall health standards. Therefore elucidating the exact strength of dental caries in relation to smoking is difficult to identify.

Studies indicate that smokers not only had bad oral hygiene and less sophisticated outlook on health, but also had different eating habits, presumably consuming higher amount of sugar containing products like soft drinks and snacks (6, 28 ). It is also seen that smokers have poorer brushing habits than non-smokers $(2,37,45)$. Also current smokers were less likely to report regular preventive visits to dentists and were reluctant to use accessory dental aids such as dental floss (42).

In natural tobacco, sugar can be present in a level up to $20 \%{ }_{\text {wt }}$. In addition, various caries promoting factors such as sugars ( $4 \%_{\text {wt }}$ or can be up to $13 \%_{\mathrm{wt}}$ and sweeteners are added intentionally during tobacco manufacturing process (67). Sugars used as cigarette additive include glucose, fructose, invert sugar (glucose/fructose mixture) and sucrose. In addition, many tobacco additives contain high amount of sugars, for example fruit juices, honey, molasses extracts, cones, maple syrup and caramel. The added sugars are usually reported to serve as flavor/casing and humectants. However, sugars also promote tobacco smoking, because they generate acids that neutralize the harsh taste and throat impact of tobacco smoke. Moreover, the sweet taste and the agreeable smell of caramelized sugar flavors are appreciated in particular by starting adolescent smokers (67).

All the findings above can be argued for increased dental caries in smokers. Though a direct etiological relation is still lacking between smoking and dental caries, the abovementioned studies and findings point to the conjecture that smoking has some influence in high caries incidence. Further studies, clinical trials and experiments are needed to confirm the independent effect of smoking as one of the causes of dental caries.

\section{Conclusion}

Smoking is evidently associated with systemic diseases like cardiovascular diseases, various lung disorders and different types of cancer. It has been proved that smoking is hazardous especially to women and children. Cigarette smoking negatively influences oral cavity. It has been established that it also causes diseases such as oral cancer, peridontitis, leukoplakia and several other oral lesions, but the direct influence of smoking on dental caries is still not verified. It has been proved that smoking along with bad oral hygiene, food habits, preventive dental visits and over all health standards, is associated with high caries incidence.

\section{Acknowledgement}

Supported by grant IGA MZ CR NR 8781-3/2006.

\section{References}

1. Adam T, Baker RR, Zimmermann R. Investigation, by single photon ionisation (SPI)-time-of-flight mass spectrometry (TOFMS), of the effect of different cigarette-lighting devices on the chemical composition of the first cigarette puff. Anal Bioanal Chem. 2007;2:575-84.

2. Ainamo J. The seeming effect of tobacco consumption on the occurrence of periodontal disease and dental caries. Suom Hammaslaak Toim. 1971;67(2): $87-94$. 
3. Al-Belasy FA. The relationship of "shisha“ (water pipe) smoking to postextraction dry socket. J Oral Maxillofac Surg. 2004;62(1):10-4.

4. Alkhatib MN, Holt RD, Bedi R. Smoking and tooth discolouration: findings from a national cross-sectional study. BMC Public Health. 2005;5(1):27.

5. Anderson P. Global use of alcohol, drugs and tobacco. Drug Alcohol Rev. 2006;25(6):489-502.

6. Axelsson P, Paulander J, Lindhe J. Relationship between smoking and dental status in 35-, 50-, 65-, and 75-year-old individuals. J Clin Periodontol. 1998;25(4) 297-305

7. Banoczy J, Gintner Z, Dombi C. Tobacco use and oral leukoplakia. J Dent Educ. 2001;65(4):322-7.

8. Bartal M. Health effects of tobacco use and exposure. Monaldi Arch Chest Dis 2001;56(6):545-54

9. Bergström J, Boström L. Tobacco smoking and periodontal hemorrhagic responsiveness. J Clin Periodontol 2001;28:680-85.

10. Bergström J, Eliasson S, Dock J. A 10-year prospective study of tobacco smoking and periodontal health. J Periodontol 2000;71:1338-47.

11. Bernhard D, Moser C, Backovic A, Wick G. Cigarette smoke - an aging accelerator? Exp Gerontol. 2007;42(3):160-5

12. Bokor-Bratic M. Prevalence of oral leukoplakia. Med Pregl. 2003;56:552-5.

13. Bruno-Ambrosius K, Swanholm G, Twetman S. Eating habits, smoking and toothbrushing in relation to dental caries: a 3-year study in Swedish female teenagers. Int J Paediatr Dent. 2005;15(3):190-6.

14. Cheng AC, Pang CP, Leung AT, Chua JK, Fan DS, Lam DS. The association between cigarette smoking and ocular diseases. Hong Kong Med J. 2000;6(2) 195-202.

15. Chopra KL. Smoking, a great health hazard. Yojana. 1988:32(10):32-3, 40

16. Darby IB, Hodge PJ, Riggio MP, Kinane DF. Clinical and microbiological effect of scaling and root planning in smoker and non-smoker chronic aggressive periodontitis patients. J Clin Periodontol 2005;32/2:200.

17. Das SK. Harmful health effects of cigarette smoking. Mol Cell Biochem. 2003; 253(1-2):159-65.

18, Dautzenberg B.Tobacco-related diseases. Rev Prat. 2004;54(17):1877-82.

19. DeLuca S, Zarb G. The effect of smoking on osseointegrated dental implants. Part II: Peri-implant bone loss. Int J Prosthodont. 2006;19(6):560-6.

20. Doll R. Uncovering the effects of smoking: historical perspective. Stat Methods Med Res. 1998;7(2):87-117

21. Etzel RA. Active and passive smoking: hazards for children. Cent Eur J Public Health. 1997;5(2):54-6.

22. Fagerstrom K. The epidemiology of smoking: health consequences and benefit of cessation. Drugs. 2002;62 Suppl 2:1-9.

23. Genco RJ. Current view of risk factors for periodontal diseases. J Periodonto 1996;67:1041-49.

24. Haas R, Haimbock W, Mailath G, Watzek G. The relationship of smoking on peri-implant tissue: a retrospective study. J Prosthet Dent. 1996;76(6):592-6.

25. Haffajee AD, Soucransky SS. Relationship of cigarette smoking to the subgingival microbiota. J Clin Periodontol 2001;28:377-88.

26. Hecht SS. Cigarette smoking: cancer risks, carcinogens, and mechanisms. Langenbecks Arch Surg. 2006;391(6):603-13.

27. Heng C K, Badner V M, Freeman K D. Relationship of cigarette smoking to dental caries in a population of female inmates. Journal of correctional health care 2006;12(3):164-74.

28. Hirsch JM, Livian G, Edward S, Noren JG. Tobacco habits among teenagers in the city of Goteborg, Sweden, and possible association with dental caries. Swed Dent J. 1991;15(3):117-23.

29. Hoffmann D, Hoffmann I. The changing cigarette, 1950-1995. J Toxicol Environ Health. 1997;50(4):307-64.

30. Hyland A, Rezaishiraz H, Bauer J, Giovino GA, Cummings KM. Characteristics of low-level smokers. Nicotine Tob Res. 2005;7(3):461-8.

31. Ide R, Mizoue T, Ueno K, Fujino Y, Yoshimura T. Relationship between cigarette smoking and oral health status. Sangyo Eiseigaku Zasshi. 2002;44(1):6-11.

32. James JA, Sayers NM, Drucker DB, Hull PS. Effect of tobacco products on the attachment and growth of periodontal ligament fibroblasts. J Periodontol 1999; 70:518-25.

33. Johnson GK, Hill M. Cigarette smoking and the periodontal patient. J Periodontol 2004;75:196-209.

34. Johnson NW, Bain CA. Tobacco and oral disease. EU-Working Group on Tobacco and Oral Health. Br Dent J. 2000;189(4):200-6.

35. Johnson GK, Slach NA. Impact of tobacco use on periodontal status. J Den Education 2001;65:313-21.

36. Kelbauskas E, Kelbauskiene S, Nedzelskiene I. The influence of smoking on ora health. Medicina (Kaunas). 2005;41(5):418-26.

37. Kelbauskas E, Kelbauskiene S, Paipaliene P. Smoking and other factors influencing the oral health of Lithuanian Army recruits. Mil Med. 2005;170(9):791-6.

38. Kervongbundit V, Wikesjo UME. Effect of smoking on periodontal health in molar teeth. J Periodontol 2000;71:433-37.
39. Kinane DF, Chestnutt IG. Smoking and periodontal disease. Rev Oral Biol Med 2000;11:356-65.

40. Lagrue G, Branellec A, Lebargy F. Toxicology of tobacco. Rev Prat. 1993 May $15 ; 43(10): 1203-7$

41. Lie MA, Loos BG, Henskens YM, Timmerman MF, Veerman EC, van der Velden $\mathrm{U}$, van der Weijden GA. Salivary cystatin activity and cystatin $\mathrm{C}$ in natural and experimental gingivitis in smokers and non-smokers. J Clin Periodontol. 2001; 28(10):979-84.

42. Locker D. Smoking and oral health in older adults. Can J Public Health. 1992; 83(6):429-32.

43. Ludwick W., Massler M. Relation of dental caries experience and gingivitis to cigarette smoking in males 17 to 21 years old (at the Great Lakes Naval Training Center). J Dent Res. 1952;31(3):319-22.

44. Ma N, Tagawa T, Hiraku Y, Murata M, Ding X, Kawanishi S. 8-Nitroguanine formation in oral leukoplakia, a premalignant lesion. Nitric Oxide. 2006; 14(2):137-43.

45. Macgregor ID. Survey of toothbrushing habits in smokers and non-smokers. Clin Prev Dent. 1985;7(6):27-30

46. Machuca G, Rosales I, Lacalle JR, Machuca C, Bullón P. Effect of cigarette smoking on periodontal status of healthy young adults. J Periodontol 2000;71:73-78.

47. Mackay J, Amos A. Women and tobacco. Respirology. 2003;8(2):123-30.

48. Mahabee-Gittens M. Smoking in parents of children with asthma and bronchiolitis in a pediatric emergency department. Pediatr Emerg Care. 2002;18(1):4-7.

49. Mehta FS, Jalnawalla PN, Daftary DK, Gupta PC, Pindborg JJ. Reverse smoking in Andhra Pradesh, India: variability of clinical and histologic appearances of palatal changes. Int J Oral Surg. 1977;6(2):75-83.

50. Müller H-P, Stadermann S, Heinecke A. Gingival recession in smokers and nonsmokers with minimal periodontal disease. J Clin Periodontol 2002;29:129-36.

51. Musk AW, de Klerk NH.. History of tobacco and health. Respirology. 2003; 8(3):286-90.

52. Nylander K, Dabelsteen E, Hall PA. The $\mathrm{p} 53$ molecule and its prognostic role in squamous cell carcinomas of the head and neck. J Oral Pathol Med. 2000;29(9): 413-25.

53. Osler M, Clausen JO, Ibsen KK, Jensen GB. Smoking as social heritage. Children whose mothers are smokers are more likely to become smokers as adults. Ugeskr Laeger. 1996;158(17):2384-7

54. Proctor RN. Tobacco and the global lung cancer epidemic. Nat Rev Cancer. 2001;1(1):82.

55. Razali M, Palmer RM, Coward P, Wilson RF. A retrospective study of periodontal disease severity in smokers and non-smokers. British Dent Journal 2005; 198:495-98

56. Reibel J. Tobacco and oral diseases. Update on the evidence, with recommen dations. Med Princ Pract. 2003;12 Suppl 1:22-32.

57. Sanchez-Perez A, Moya-Villaescusa MJ, Caffesse RG. Tobacco as a Risk Factor for Survival of Dental Implants. J Periodontol. 2007;78(2):351-59.

58. Saraswathi TR, Ranganathan K, Shanmugam S, Sowmya R, Narasimhan PD, Gunaseelan R. Prevalence of oral lesions in relation to habits: Cross-sectional study in South India. Indian J Dent Res. 2006;17(3):121-5.

59. Sato K, Endo S, Tomita H. Sensitivity of three loci on the tongue and soft palate to four basic tastes in smokers and non-smokers. Acta Otolaryngol Suppl. 2002; (546):74-82

60. Schepman KP, Bezemer PD, van der Meij EH, Smeele LE, van der Waal I. Tobacco usage in relation to the anatomical site of oral leukoplakia. Oral Dis. 2001;7(1):25-7.

61. Schmidt HJ. Tobacco smoke and the teeth. Stoma (Heidelb). 1951;4(2):111-25.

62. Shenkin JD, Broffitt B, Levy SM, Warren JJ. The association between environmental tobacco smoke and primary tooth caries. J Public Health Dent. 2004; 64(3): 184-6

63. Šimůnek A, Kopecká D, Brazda T, Somanathan R.V., Bukač J. Povrchova úprava implantatu zavadenych při operaci sinus lift. Quintessenz, 2006, 1,55-59.

64. Somanathan R.V., Simunek A., Bukac J., Brazda T., Kopecka D.: Resonance frequency analysis of dental implants placed into the sinus lifts: at stage 1 and stage 2 surgery. Ces Stomat. 2006, 4:111-14.

65. Soysa NS, Ellepola AN. The impact of cigarette/tobacco smoking on oral candidiasis: an overview. Oral Dis. 2005;11 (5):268-73

66. Strumylaite L, Kregzdyte R, Vaitkaitiene E Passive smoking and respiratory health of children. Medicina (Kaunas). 2005;41(4):348-54

67. Talhout R, Opperhuizen A, van Amsterdam JG. Sugars as tobacco ingredient: Effects on mainstream smoke composition. Food Chem Toxicol. 2006;44(11):1789-98.

68. Tanner ACR, Kent RJr, Van Dyke T, Sonis ST, Murray LA. Clinical and other risk indicators for early periodontitis in adults. J Periodontol 2005;76:573-81.

69. Tomar SL, Winn DM. Chewing tobacco use and dental caries among U.S. men. J Am Dent Assoc. 1999 Nov;130(11):1601-10. Erratum in: J Am Dent Assoc 1999;130(12): 1700 .

70. Van Winkelhoff AJ, Bosch-Tijhof CJ, Winkel EG, Van der Reijden WA. Smoking affects the subgingival microflora in periodontitis. J Periodontol 2001;72:666-71. 
71. Wald NJ, Hackshaw AK. Cigarette smoking: an epidemiological overview. Br Med Bull. 1996;52(1):3-11.

72. Williams SA, Kwan SY, Parsons S. Parental smoking practices and caries experience in pre-school children. Caries Res. 2000;34(2):117-22.

73. Winn DM. Tobacco use and oral disease. J Dent Educ. 2001;65(4):306-12.

74. Wirth N, Abou-Hamdan K, Spinosa A, Bohadana A, Martinet Y. Passive smoking. Rev Pneumol Clin. 2005;61(1 Pt 1):7-15.
75. Yach D, Wipfli H. A century of smoke. Ann Trop Med Parasitol. 2006;100(5-6): $465-79$

76. Yuca K, Calka O, Kiroglu AF, Akdeniz N, Cankaya H. Hairy tongue: a case report. Acta Otorhinolaryngol Belg. 2004;58(4):161-3.

77. Zitterbart PA, Matranga LF, Christen AG, Park KK, Potter RH. Association between cigarette smoking and the prevalence of dental caries in adult males. Gen Dent. 1990;38(6):426-31.

Submitted March 2007. Accepted July 2007.

\section{Corresponding author:}

Dr. Sajith Vellappally, B.D.S, Faculty of Medicine, Department of Hygiene and Preventive Medicine, Šimkova 870, 50038 Hradec Králové, Czech Republic, e-mail: drvellappally@rediffmail.com 